\title{
QUANDO O ARTISTA TRAMA UMA IMAGINAÇÃO MUSEAL. ANTÔNIO BANDEIRA E A CRIAÇÃO DO MUSEU DE ARTE DA UNIVERSIDADE DO CEARÁ
}

\author{
Carolina Ruoso \\ Universidade Paris I
}

"Quand l'artiste trame une imagination muséale. Antônio Bandeira et la création du musée d'art de l'Université du Ceará"'

RESUMO:

O presente artigo busca investigar na obra do artista Antônio Bandeira os indícios da sua imaginação museal. Analisa o pintor e a sua participação no fazer-se do mundo das artes em Fortaleza, antes da criação do Museu de Arte da Universidade Federal do Ceará. E procura interpretar o significado de cadinho, este objeto-conceito, presente de maneira marcante na vida e na obra do artista. Na relação com a sua história familiar: a fundição do pai, o conhecimento do conceito de cadinho de raças entre os artistas ligados ao Bandeira, bem como críticos de arte e nos escritos autobiográficos de Bandeira. $\mathrm{O}$ artigo procura historicizar o conceito de cadinho de raças e sua repercussão no Brasil, como argumento que fundamentou a invenção de uma identidade nacional Brasileira, baseada na homogeneidade cultural. Procurando estabelecer semelhanças e diferenças entre a apropriação de Bandeira do cadinho e o projeto da nação brasileira. Para apontar algumas possíveis definições para o que viria a ser o museu-cadinho de Antônio Bandeira.

\section{PALAVRAS-CHAVE:}

Imaginação museal. Museus de arte. Cadinho de raças. História dos museus. Museu Universitário.

\section{RESUMÉE:}

Cet article propose étudier les indices de l'imagination muséale de l'artiste Antonio Bandeira. L'analyse du peintre et de sa participation à la composition d'un monde de l'art à Fortaleza, avant la création du Musée de l'Université Fédérale de Ceará. Et il cherche à interpréter le sens de creuset, cet objet-concept, marquée dans la vie et l'œuvre de l'artiste. Dans le cadre de son histoire familiale: le creuset du père, la connaissance du concept de melting-pot pour les artistes liés a Bandeira, ainsi que les critiques d'art et les écrits autobiographiques de Bandeira. Le présent article vise à historiciser le concept de melting-pot et sa résonance au Brésil, un argument qui a justifié l'invention d'une identité nationale brésilienne fondé sur l'homogénéité culturelle. On a cherchez à établir des similitudes et des différences entre l'appropriation du creuset par Bandeira et de la conception pour la nation brésilienne. Pour souligner quelques définitions possibles de ce qui allait devenir le musée-creuset deAntonio Bandeira.

\section{MOTS CLÉS:}

Imagination muséale. Musées d'Art. Creuset de races. Histoire des Musées. Musée Universitaire.

I * Carolina Ruoso é doutoranda em História da Arte na Universidade de Paris I, Panthéon-Sorbonne com orientação do professor Dominique Poulot. É membro organizadora do Groupe de Travail em Histoire du Patrimoine et des Musées HiPaM, neste mesmo programa de pós-graduação. Bolsista da CAPES. E-mail: carol@ruoso.com. 
O artista Antônio Bandeira recebeu, no inicio desta pesquisa, uma atenção especial em relação ao trabalho de investigação que venho realizando para contar a história da formação do Museu de Arte da Universidade Federal do Ceará (MAUC). O percurso deste artista que nasceu na cidade de Fortaleza em 1922 e, faleceu em Paris, aos 45 anos, tem me convidado a pensar a formação do museu a partir da compreensão do seu fazer artístico e da construção da sua participação no mundo das artes. De acordo com BECKER (20 I0:58-63) o mundo das artes é composto por todos aqueles que estão envolvidos na produção das obras, as quais são definidas, por estes atores, como obras de arte, ao incorporarem esquemas estabelecidos e agirem por meio de redes de cooperação, onde há partilha de conhecimentos e convenções que possibilitam e facilitam a realização de atividades coletivas. Os artistas e os trabalhadores de museus, por exemplo, fazem parte do mundo das artes.

Assim, foi buscando compreender como uma rede de cooperação foi formada entre artistas e os demais participantes do projeto MAUC, que tornou-se necessário investigar o papel de Antônio Bandeira na tarefa de inventar um museu de arte em Fortaleza. Ao investigar o papel dos artistas na produção das memórias das artes, ao traçar a maneira pela qual estes atores interferiram instaurando diferenças e qualificando continuidades nas práticas e, no pensamento museológico, podemos perceber que o museu é produto de uma atividade coletiva. Neste artigo, procuro identificar e apontar, na obra e na trajetória de Bandeira, alguns dos indícios de uma possível imaginação museal. E, assim, construir contrapontos para traçar uma relação entre a imaginação deste artista e a formação da coleção do MAUC.

Será que um artista pode ser considerado um imaginador museal? Teria Antônio Bandeira sonhado propor um museu de arte na sua cidade? É possível ler e interpretar traços de uma imaginação museal a partir de sua obra? $O$ artista nos deixou algumas pistas... Para poder analisar e construir esta problemática utilizo o conceito de imaginação museal elaborado pelo museólogo Mário Chagas (2009), segundo o autor a imaginação museal é a capacidade única e eficaz que uma pessoa tem de articular no espaço uma narrativa poética das coisas, que começa com o estudo da "linguagem das coisas". E, a análise dessa imaginação é, também, uma forma de investigar sobre o domínio das políticas museais. Tecnicamente, ele se refere a um conjunto de pensamentos e práticas de certos atores que produziram a respeito dos museus e da museologia. Então, é a partir da investigação da imaginação museal que poderemos compreender como Antônio Bandeira participou, entre jogos de poder, da criação do MAUC.

\section{Ambiência para engendrar um museu de arte}

O MAUC não foi uma ideia de um só autor, houveram alguns artistas e intelectuais em torno da sua criação. Trata-se de um museu universitário público federal, do início da segunda metade do século $X X$, pensado para uma cidade que não tinha nenhum lugar dedicado à memória das artes. Havia um Museu de História e Antropologia circunscrito ao Ceará, criado em 1932 e, que trazia em sua coleção, quadros que haviam sido encomendados para retratar personagens e eventos, valorizando os denominados vultos da história. $\bigcirc$ trabalho deste museu não era aceito de maneira positiva por parte dos artistas de Fortaleza, talvez não concordassem com a visão da arte como ilustradora dos fatos históricos, ou 
ainda, não aprovassem a maneira pela qual os quadros eram arrumados nas salas do museu. Na solenidade de abertura do II salão de abril, em 1946, Mario Baratta fez um discurso valorizando o trabalho desenvolvido pela Sociedade Cearense de Artes Plásticas (SCAP), destacou a "evolução artística" das pinturas expostas na segunda edição do salão, resultado de 6 anos de atividades e, continuou:

(...)Aí está no Museu Histórico do Estado. O que lá se mostra, com raras exceções, é (refiro-me a quadros e retratos) de um nível artístico tão baixo (...) no mesmo caminho marcham nossas praças. Nelas não encontramos mais monumentos como o de $\mathrm{D}$. Pedro II, o do romancista $O$ Guarani, o busto de J da Penha, o monumento de Sampaio ou de Tibúrcio. $O$ que agora se colocam em nossas praças se não se envergonham o nosso povo, que pouco sabe sobre arte, deveriam envergonhar os autores. (ESTRIGAS, 2009: 47)

Aparentemente para Mário Baratta o mal-estar estava na qualidade das obras expostas no museu e nas praças. A sua queixa indica um descontentamento por parte dos artistas, pois o Governo do Estado, alvo dos ataques de Baratta, não havia elaborado políticas de cultura.Afirmava, no seu discurso,"que o povo pouco sabe sobre arte" e, que as mostras de arte organizadas pela SCAP tinham "(...) sempre mais fim educativo que econômico" (idem), deixando claro que era preciso formar um público, que o Estado deveria adquirir obras de arte e estimular a circulação dos artistas com as suas obras em exposições organizadas em outras cidades e países. Esse discurso é uma denúncia social da situação dos artistas do Estado do Ceará e, principalmente, da cidade de Fortaleza. Mario ainda conclui que é preciso ficar com os artistas, somente assim seria garantido uma "arte perene" e, onde podem ficar os artistas? Um museu de arte, poderia ser uma das respostas? No museu a permanência do artista estaria garantida enquanto parte de uma memória das artes. Mario afirmou: "gostaríamos 'de espaços para' expor nossa arte” (ibidem) (as palavras destacadas foram acrescidas por mim).

Então, havia uma preocupação, sobretudo dos artistas, com a conquista de um espaço de exposições e de políticas de aquisição pública de obras de arte. Naquele contexto, a educação artística através dos museus constituía com um desafio de difícil acesso e, geralmente, eram, em sua maioria, as elites que podiam viajar e participar de atividades culturais em outras cidades do país, principalmente, às cidades do Rio de Janeiro e São Paulo ou, ainda, ir à Europa e aos Estados Unidos. Entretanto, os deslocamentos entre as diferentes cidades pelas quais alguns artistas circulavam e, também, a prática do compartilhamento de informações sobre arte, comentando das viagens, dos livros e das revistas que liam, favorecia uma ambiência imaginativa entre os artistas e intelectuais que atuavam, à época, em Fortaleza.

Os espaços de aprendizagens e trocas de saberes aconteciam no seio dos seus pequenos grupos. No começo do século $X X$, a maior parte dos artistas da cidade faziam o trabalho de pintura de faixas e painéis publicitários e, também, coloriam fotografias e as ampliações de retratos nos estúdios Valter Severiano e Photo Ribeiro. Normalmente os encontros para falar sobre arte eram nos ateliês, seus espaços de trabalho. E após as rodas de conversa, acontecia a vida boêmia e, foi dessa maneira, que se estabeleceram as primeiras redes de artistas em Fortaleza. Como nos mostra Galvão:

Um exemplo foi o grupo que se reunia no atelier de fazer letreiros de Delfino Silva, na rua Pedro Pereira, um pequeno espaço que já havia 
sido ateliê de J. Carvalho antes deste artista se transferir para o Rio de Janeiro.Todas as tardes, depois das 4 da tarde, quando a calçada jà estava na sombra, chegavam muitos artistas, que desviando-se dos vidros dos letreiros que Delfino estava pintando e evitando se sujar de tinta, sentavam-se em tamboretes e caixotes para conversar sobre arte. (2008: 77)

Foi após ter participado de alguns destes encontros que Mario Baratta, um jovem estudante de Direito, com as ideias da "Semana de Arte Moderna » na bagagem - que havia trazido na mudança, quando partiu do Rio de Janeiro organizou, ao lado dos seus colegas estudantes, o primeiro Salão de Abril, em 1943. E, num exercício de mobilização, começou a bater na porta de cada um dos diferentes ateliês da cidade para convidar os artistas para formar o CCBA Centro Cultural de Belas Artes e, depois a SCAP, Sociedade Cearense de Artes Plásticas. Estes espaços permitiram criar um ambiente mais institucionalizado, onde eles podiam estar juntos para falar de arte, para trocar livros e experiências e, principalmente, fazer o que Mario Baratta chamava à francesa de "entre aide", que era fazer avaliações mutuas das suas pinturas.

Todos os trabalhos eram submetidos à critica do conjunto e a ninguém cabia magoar, pois a critica era honesta e procurava mostrar falhas, erros que deveriam ser evitados. Era critica construtiva. Hoje sem atelier, não há mais o lugar onde possa, o artista, deixar que os companheiros se critiquem mutuamente suas realizações. Nunca $\circ$ nosso grupo mostrava ao público tudo o que produzia, mas apenas aquilo que passava na critica, o que de melhor produzia. No atelier, havia aquilo que os franceses chamavam de entre aide, que estimulava. (ESTRIGAS, 2004: 31-32)

Destaco neste depoimento, o uso da expressão francesa "entraide", que quer dizer ajuda mutua, para comentar brevemente sobre o tema da influência estrangeira. Baratta poderia estar construindo a sua imagem de homem da cultura, ao fazer uso de um estrangeirismo, demarcando dessa maneira, a amplitude do seu conhecimento diante dos seus pares. Podemos, também, aproveitar este indicio para mostrarmos que estes artistas organizados em sociedade, poderiam ter tido conhecimento que em Paris os artistas também praticavam "entraide" por vias associativas, muitas vezes estimulados por donos de galerias de arte, através de ajudas familiares, para garantir aos artistas uma renda mínima. Foi uma prática que aconteceu nos anos 1930, uma alternativa encontrada para atravessar a crise provocada pela quebra da bolsa de Nova York. (VERLAINE, 2012: 23) Se no caso francês a "entraide" significava uma ajuda financeira, em Fortaleza embora fosse uma forma de cooperação financeira era, sobretudo, de aprendizados e de ideias: astúcias para fazer dos sonhos realidade.

A articulação gerada nesses encontros alimentada pelos sonhos comuns, os mobilizava a inventar e a produzir as exposições, os cursos e as reuniões semanais. Entre as ações de ajuda mútua, atuavam, simultaneamente, como: críticos de arte, curadores, juri, colecionadores e produtores culturais. Eles eram escritores, operários, estudantes, profissionais liberais, funcionários e pintores. $\mathrm{E}$ começaram a ter desejos maiores, apercebendo-se que para realizá-los, fabricavam suas próprias necessidades, mas não eram capaz de produzirem tudo que almejavam dentro daquilo que entendiam ser o mundo das artes que estavam construindo, com a experiencia, notavam que faltavam condições e incentivos 
na cidade que proporcionassem visibilidade ao que estavam nomeando de arte. Não estagnaram-se e continuaram as atividades coletivas, sendo insistentes e, sempre que oportuno, reivindicavam publicamente as suas queixas e demandas. O auxílio que tivemos até hoje dos poderes públicos resumiu-se na compra de, se não me engano, dois trabalhos expostos, pelo ex-Departamento de Imprensa e Propaganda.Também a Prefeitura Municipal de Fortaleza deixou que vivêssemos uns três meses trepados nos saIões em ruínas da velha e histórica Intendência. (...) Hoje caso pudéssemos pleitear alguma coisa dos poderes públicos, o que poderíamos querer seria uma possibilidade para levar um salão nosso à Metrópole. (ESTRIGAS, 2009: 47-48)

Uma atividade bastante valorizada entre os Scapianos era o curso de pintura ao ar livre, que aconteciam na maioria das vezes no Morro do Moinho e Pirambu. Eles escolhiam um bairro popular para aprender a pintar a luz, as paisagens da cidade e suas percepções criticas do social. Estes bairros eram favelas de ocupação, que eram herdeiras dos antigos campos de refugiados da seca que foram submetidos ao campo de concentração, criado pelo governo da província do Ceará em 1933 (RIOS, 200I). Um lugar pensado para as pessoas que eram rejeitadas pela cidade de Fortaleza, pessoas que deveriam ser esquecidas. $O$ gesto de pintar e fotografar esse lugar produziu uma lembrança e, associou a imagem dos artistas à história do bairro, gerando uma intervenção na memória da cidade, produzindo imagens que de alguma maneira narram, fabricando fragmentos de lembranças que impedem, de uma certa maneira o silêncio. Esta ação de artista no exercício do aprendizado era, também, uma demonstração de um engajamento politico pois a escolha destes artistas não era ingênua, tratava-se de um posicionamento sobre a maneira pela qual queriam estar/ser no mundo. Gestos que marcaram a época em que iniciavam uma reflexão sobre um projeto que começavam a nomear de "Arte-Ceará".

Foi durante uma caminhada com destino ao Morro do Moinho, que Bandeira foi avistado em frente a sua casa na rua Princesa Isabel e, convidado por Mario Baratta a fazer parte das atividades, como lembrou o artista Afonso Bruno em entrevista concedia ao Estrigas no ano de 1974:

Em fins de dezembro de 1941, ao passarmos pela rua Dona Isabel, "achamos" Antônio Bandeira na porta da sua residência. Embora ele parecesse ainda leigo em pintura, Baratta o convidou para a excursão que fazíamos ao Morro do Moinho. Bandeira seguiu-nos, e tudo indica que foi ai que ele pegou em pincel pela primeira vez, mas surgiu então a sua comentada aquarela Três por dois vinténs. (ESTRIGAS, 1983:80)

Bandeira iniciou-se nas artes com a Dona Mundica, professora do bairro, aprendendo a copiar reproduções de obras de arte dos cartões postais. Ele havia despertado o interesse pelas artes quando era pequeno e pertencer a um grupo, poder deslocar-se na cidade em bando, compartilhar ideias, técnicas, organizar e participar de exposições, são elementos inovadores e que atraíram Bandeira. A inciativa daquele grupo que, posteriormente, fundaria a SCAP, formavam uma escola invisível (GALVÃO 2008). Muitos foram os artistas que participaram dos cursos e tornaram-se membros da Sociedade Cearense de Artes Plasticas, não havia uma homogeneidade entre eles, eram diferentes assim como seus projetos, alguns de cunho mais individual outros pensados para o 
coletivo ou para a cidade. Neste sentido, dentre o conjunto de pensamentos e práticas realizados e idealizados por estes artistas, que faziam parte da SCAP, germinaram "imaginações museais" distintas.

O que tenho percebido é que provavelmente houveram varias dessas imaginações: enquanto sonhos, enquanto necessidades culturais ou enquanto modelo à seguir para um lugar dedicado à memória das artes em Fortaleza e, também, por um espaço disponível aos artistas. Neste artigo o objetivo é tecer a perspectiva de um único ator, Antônio Bandeira.

\section{Da criação do Museu de Arte da Universidade do Ceará}

O MAUC foi inaugurado no dia 25 de junho de 196I.A SCAP fechou suas portas em 1958. O museu não foi um projeto pensado para dar continuidade à SCAP. Como o MAUC foi pensado enquanto projeto público e político? A criação do MAUC significou uma importante mudança no campo artístico de Fortaleza porque ele representou a primeira iniciativa na construção de uma política pública de cultura no Ceará. Depois do MAUC, houveram muitas iniciativas geridas pelo Governo do Estado, Prefeitura e iniciativa privada, especialmente dedicadas ao domínio artístico: galerias, museus, a Secretaria de Cultura do Governo do Estado do Ceará (fundada em 1966) e o Salão de Abril passa para a responsabilidade da Prefeitura Municipal de Fortaleza, no ano de 1964.

A instalação do museu de arte provocou uma alteração da paisagem cultural em Fortaleza. Esta preocupação institucionalizada em prol da construção de uma memória para as artes teria causado incômodos, controvérsias e tensões? Seriam iniciativas derivadas da SCAP? Houveram ramificações que conquistaram seus próprios caminhos e, assim, conseguiram ter um lugar e desenvolver seus papéis na cidade. O Mauc foi pensado como um museu de muitas missões? Como a análise das imaginações museais em torno do Mauc, podem nos fornecer argumentos para descrever tais missões?

Ainda antes da inauguração do MAUC, o artista Chico da Silva iniciou um período de residência, entre 1959 à 1963 . Ele havia sido convidado a pintar telas em uma das salas previstas para o museu, recebeu materiais como pinceis e tintas e pintou 39 telas que ficaram como parte da coleção do acervo. O Reitor da Universidade Federal do Ceará,Antônio Martins Filho, depois de uma viagem que fez à Paris, entre 1949 e 1959 e, de ter falado com Heloísa Juaçaba, Zenon Barreto e Floriano Teixeira, tomou para si a responsabilidade de criar um museu, devido a forte constatação da importância de um museu para o aprendizado mais aprofundado sobre arte. Então, Chico da Silva foi a primeira experiencia de ação, antes mesmo da sua existência oficial.

Foi o artista Jean Pierre Chabloz quem pediu ao Reitor que recebesse Chico da Silva.I Chabloz era um artista Suíço, funcionário do SENTA (Serviço Especial de Mobilização de Trabalhadores para a Amazônia) e, também, membro da extinta SCAP. Ele viu Chico, na praia do peixe, a pintar um muro e acreditou ter encontrado o artista primitivo, o que ele qualificava como sendo o "reinventor da pintura". Martins Filho ao compreender o olhar de Chabloz, recebeu Chico na Universidade. $O$ projeto do museu começou com a formação de uma da coleção e com a ideia de uma arte que poderia ser nomeada de primitiva, considerada como uma arte verdadeiramente brasileira, pura e original, estas

I Arquivo do Museu de Arte da Universidade Federal do Ceará: Caixa Chico da Silva. 
noções fizeram parte da escolha museal. Entretanto, na biografia difundida de Chico da Silva, não aparecem os registros de que seus quadros teriam sido expostos na ocasião da inauguração do MAUC (OLIVEIRA, 20I0)

Para a exposição inaugural do Museu o artista escolhido foi Bandeira, que também já havia circulado na Europa, mas antes havia exposto em sua cidade, em São Paulo, Rio de Janeiro e Salvador. No caso, ele representava o artista que retornou, uma imagem muito forte para fabricar memórias. Antônio tinha consciência do verbo "emigrar", para ele, no Ceará, até mesmo os artistas eram imigrantes, refugiados, flagelados que precisavam partir para poder ser artista. "O único meio é emigrar (...) no Nordeste até os artistas são flagelados”2 Durante as semanas que antecederam a exposição, os jornais locais publicaram muitas matérias sobre o artista que era muito reconhecido em São Paulo, Rio de Janeiro e Paris e que havia voltado para casa, especialmente para inaugurar o primeiro museu de artes da cidade. Ele havia conseguido realizar o mais difícil, talvez o quase impossível, o sonho da maioria dos exilados, voltar em grande estilo à terra natal.

Com este gesto, foi construída uma nova possibilidade para os artistas, ao saberem que, mesmo partindo, iriam ter um lugar de memória, ou melhor, lugares de memórias que representassem a possibilidade de ligação entre os artistas e a cidade. Uma chave para inscrever a saudade ou para entrar pela porta da história da arte? A necessidade de partir aliada ao sonho de retorno, por parte dos artistas ficou registrado, na musica "O Carneiro" de Ednardo e Augusto Pontes, que:

(...) é um exemplo, da permanência do significado do Rio de Janeiro, para aqueles que, oriundos de outras regiões do Brasil, mais especificamente do Nordeste, já existente como região distinta do Norte, pretendiam dedicar-se a carreira artista na década de 1970. Não é somente a letra que confirma este fato, a melodia também, marcada pelos ritmos de origem nordestina como o baião e o forró, mistura-se aos traços rítmicos da geração que naqueles anos ficou conhecida como o "Pessoal do Ceará". Na musica vemos que o Rio de Janeiro era o lugar para onde se ia, afinal, "as coisas vem de lá" e de onde se voltava, mas em videotapes e revistas super coloridas. (BEZERRA, 2009: 8I)

E para colocar em evidência esta noção de pertencimento, Antônio Bandeira prepara uma homenagem à cidade de Fortaleza. Seus quadros foram adquiridos pela Universidade do Ceará e ele oferecia uma de suas telas, essa que ele intitulou "Cidade Queimada do Sol" e um poema aos filhos da terra. Ele pretendia mostrar com esta atitude, como a sua obra que tornava-se coleção do museu, estava carregada de afetividade. $E$, sobretudo que ele nunca havia esquecido sua terra e suas gentes e que seu trabalho era em parte Fortaleza e em parte Paris. Como diz na letra da canção de Sérgio Ricardo "Tulão das estrelas":"É do povo: sofrimento traz sabedoria / Filho que sai da terra volta diferente /Volta trazendo uma vontade dentro /volta trazendo uma vontade dentro!". Essa diferença e essa vontade dentro, foi o que fez germinar a criação de sua "imaginação museal".

\section{Fortaleza um xadrez queimado do sol: pintura e poesia do afeto-cidade}

Antônio Bandeira utilizou a pintura à óleo, aplicada com pincéis e espátulas sobre tela de tecido. Ele escolheu a pintura à óleo, talvez porque uma das vantagens

2 "Nomes que lideram o movimento atual da pintura neste Estado deixarão brevemente nossa terra, com destino ao Rio de Janeiro". O Unitário. Fortaleza, I 3 mar. 1945. 
dessa técnica é a flexibilidade e a secagem lenta da pintura, permite ao artista modificar e corrigir seu trabalho em permanência ${ }^{3}$. Sua intenção não era os corrigir, mas brincar a partir da longa duração do tempo com os movimentos imprecisos dos fios de tinta molhados. Ele sabia trabalhar o tempo de secagem ao seu favor, com esperteza ele mexia o quadro para fazer a tinta escorrer sobre a tela nas diversas posições, a fim de que as imagens criadas ajudassem a formar sua composição abstrata, aproveitando da ocasião para misturar as cores, sobrepondo-as.

O vermelho escarlate é a cor do pano de fundo, com nuances entre intensidades mais ou menos diluídas da tinta, chapada na tela. Essa é a cor que dá a estrutura e, também, a força temática do quadro. Uma cor quente que marca uma diferença com a maior parte dos seus quadros da coleção do Mauc. $O$ vermelho era necessário para representar a ideia de "queimar" a cidade.As outras cores formam o traçado xadrez: azul, preto, fragmentos de quadrados e linhas retas, inventam a cartografia de Fortaleza, suas ruas e suas casas. Os amarelos e brancos são as faíscas, talvez para fabricar os pontos de tensão e luz, da força do calor quando a cidade ferve. Revelando a ideia de poder fundir misturando essas cores que são diferentes, mas que estão ainda lá, presentes e distintas. E o quê faltava para tudo misturar? Por quê ele não fazia tudo vermelho, amalgamado? Ao observar seus quadros, poderia afirmar que o quê interessava ao Bandeira não era $\circ$ produto final? E, sim o fazer-se, o queimar-se? No entanto, o título da tela marca um processo concluído: a cidade queimada do sol. Mesmo tendo sido queimada a cidade não tornou-se homogênea para o artista, embora em ambiguidade, o vermelho predomine intensamente.

Para compreender o pensamento e a produção de Bandeira partimos também da leitura do seu lugar social. Antônio era filho de metalúrgico, dono de uma pequena fundição, que prestava serviços gerais de mecânica e, que tinha como função principal, a fundição e a usinagem de peças fundidas. Somente em 1954, há um salto para a produção das bombas de puxar água e a criação da fabrica, tendo como carro chefe as Bombas Neide, e um corpo de 30 a 40 trabaIhadores ${ }^{4}$. Tendo nascido neste contexto, mesmo não vendo-se no mesmo oficio do pai, Bandeira sempre trouxe consigo, a presença desse fazer, como registrou na sua poesia dedicada à Fortaleza.

Bandeira homenageia sua cidade mas, principalmente o seu público. Ele faz um elogio do seu público: pessoas de uma cidade moderna, que não tinha segundo ele nada de provinciano e de folclórico. A poesia está associada ao texto de Bandeira, datado de 1963, apresentando as obras que passavam a fazer parte do acervo do MAUC5. Para ele as pessoas estavam prontas para ver e saber compreender as suas pinturas. A partir do seu texto, podemos interpretar que ele tinha uma expectativa ao fazer a crítica de sua arte, oferecia ao público as coordenadas, explicando que não era necessária explicação, para definir o seu trabalho. Aplicava o que Peter Gay (1988) denominou de "educação dos sentidos" qualificando o olhar espontâneo do publico, pedindo uma atenção ao sentimento do amor, do carinho, de angustia e, até mesmo, do prazer de viver. Ele tinha vontade de construir um diálogo e afirmava que Fortaleza havia a mesma possibilidade de compreensão da obra de arte que Paris, Londres e Rio-São

3 Girão Eduardo. Antônio Badeira:amazonas guerreando. 201 I. In: http://eduardogirao.blogspot.fr/201 I/07/ antonio-bandeira-amazonas-guerreando.html acessado em maio de 2012.

4 Correspondências trocadas com Nilson Bandeira, sobrinho de Antônio Bandeira, responsável pela pagina Pintor Antônio Bandeira, no facebook, via mensagem, entre os dias 02 e 30 de janeiro de 2013.

5 Arquivo do Museu de Arte da Universidade Federal do Ceará: caixa Antônio Bandeira - DOC04/06. Texto de 1963, datilografado, com alterações manuscritas, feitas por Antônio Bandeira. 
Paulo. E, como ele olhava para Fortaleza como um filho da terra, ao mesmo tempo que reunia a experiencia do viajante, ele acreditava estar em uma cidade que havia despertado para os grandes acontecimentos de cultura e de sensibilidade.

\author{
Bom dia \\ Fortaleza \\ Te ofereço \\ êsse carinho de viajor \\ do filho \\ que não sabe \\ se vem ou se vai \\ o que olha e medita \\ indo e voltando \\ à sua cidade \\ envelhecendo e remoçando \\ com ela (ela és tu) \\ Fortaleza \\ te ofereço \\ êsse carinho de gente \\ para outra gente \\ (porque é gente a que \\ nasce de teu ventre) \\ de corpo e alma também \\ ofereço \\ cadinho de ferro e bronze \\ (uma lembrança de meu pai) \\ cadinho de corpo e alma \\ êsse cadinho de raças \\ Fortaleza \\ Antônio Bandeira
}

Ainda na tarefa elogiosa da cidade Bandeira evidenciava o seu retorno atribuindo importância:à luz do sol, ao balançado na rede, à brisa, ao mar e às gentes. Ele descrevia a sua visão de Fortaleza com as palavras: esplendor e miséria, deixando claro sua crença na solidariedade entre as pessoas. Essa cidade moderna e contraditória, capaz de compreender a sensibilidade de uma pintura era também lugar de diferenças e desigualdades. Uma cidade moderna que começava a crescer com a vinda dos migrantes, pessoas que queriam fugir da dureza da terra árida, que procuravam um trabalho, como Chico da Silva, por exemplo que morava no Pirambu e fazia um pouco de tudo, "bicos" para sobreviver.

Mas para Bandeira não era essa imagem a ser valorizada sobre Fortaleza, ele queria mostrar uma cidade cosmopolita que olhava o passado, o presente e o futuro ao mesmo tempo. Uma cidade que tinha vontade de estar ligada ao mundo, que se interessava pelas praticas tradicionais mas sonhava com as novidades e queria aprender com os outros. Foi com estas palavras que construiu o seu retorno, a recepção da sua pintura e, também, a justificativa para ela ter sido adquirida pelo Reitor, passando a fazer parte do acervo do MAUC. Soube jogar com as duas possibilidades, de estar em Paris e chegar em Fortaleza. Não é uma história regional da arte cearense o projeto em questão, nem a valorização das culturas tradicionais como símbolos de um "ser cearense". O MAUC inscreve-se 
como narrador de si para si, de si para o outro e, dos outros para si, tramando as teias do que poderia ser a prática do lema do Antônio Martins Filho, Reitor da Universidade Federal do Ceara, à época:"o universal pelo regional”.

\section{O museu-cadinho de Bandeira}

O objeto mais evocado por Bandeira foi o cadinho. $O$ artista o tinha arraigado à vida e ao seu fazer artístico. Está para além da metáfora, é marca da experiencia do trabalho do pai, operário que tinha a habilidade de transformar o estado da matéria ao controlar o calor. O cadinho esta presente na poesia, nas entrevistas, nas fotografias, no roteiro do filme "O colecionador de crepúsculos" e no MAUC.

Cadinho ou crisol segundo a definição do dicionário (MICHAELIS, 20I2) é:

I Vaso de argila refratária, porcelana, grafita, ferro ou platina, geralmente em forma de tronco de cone, e próprio para nele se fundirem metais e outros minerais; crisol. 2 Parte do forno em que se realiza a fusão. 3 Prova: $O$ cadinho da experiência.

Para Antônio foi um objeto muito familiar, portador de memória afetiva. Pois o transportava para a fundição do seu pai, senhor Sabino Bandeira. Talvez houvesse uma imensa vontade de retribuir ao seu pai os ensinamentos de um oficio, por não ter podido seguir o sonho do seu pai, dando continuidade à Fundição Princesa Isabel. Foi sua mãe quem notou o gosto do menino para a arte e o matriculou no curso de desenho, onde aprendeu a copiar olhando cartões postais. Este cadinho de seu pai o tocou profundamente e ao mesmo tempo era utilizado para colocar em evidencia o que havia de simbólico na sua pintura. Em entrevista concedida ao seu amigo, o poeta Milton Dias, no ano de 1964, ele disse:

Da fundição aprendi misturas que meu pai nem suspeita mas, vendo derreter ferro ou bronze, aprendi muito. Hoje misturo emoções em cadinhos iguais aos dele, de ferro, de bronze, de corpos, de alma, de vento, de paisagem, de objeto, e dessa mistura fabrico as peças do meu trabalho. (ESTRIGAS e DIAS, 1992: 16)

Esse cadinho que se repete, que ele carrega consigo por todos os lugares onde passa é o que representa a sua maneira de ver e interpretar o mundo. Ele via a sua pintura como uma pratica de amalgamar as ideias, as cores, as vidas e as técnicas, Fortaleza, Paris, a si próprio e aos outros. Ele tinha uma visão que apagava os conflitos e as diferenças? O cadinho de Bandeira tinha o poder de misturar tudo a ponto de transformar tudo em uma única unidade? Ao que parece, são misturas plurais, talvez o resultado pudesse vir a ser algo uníssono, mas a pesquisa que desenvolvia este artista procurava identificar as diferenças, os nuances e as faíscas de um cadinho em ebulição. Era o poder que o cadinho tinha de fazer um conter no outro, mas isso não significava necessariamente que a transformação por meio das misturas gerasse um produto que anulava as diferenças. Ao contrário o seu trabalho de pesquisa com as cores, por meio da mistura, possibilitava o encontro com imagens as mais diversas. Seria possível saber quando e como Bandeira conheceu o conceito "cadinho de raças"? Não encontramos uma resposta precisa, mas temos exemplos do uso desses conceitos próximos ao artista. 
No dia $1^{\circ}$ de julho de 1945, Mario Baratta escreveu um texto intitulado "Exposição cearense" em resposta ao texto de Ruben Navarra apresentando a exposição na Galeria Askanasy, no Rio de Janeiro. Segundo Couto (2009: 75) embora a exposição não tenha recebido muito destaque, alguns críticos ressaltaram a oportunidade de entrar em contato com a pintura do Nordeste. E Navarro, teria celebrado as pinturas vindas do interior, com seu seu ar de pureza, sensualidade e violência, marcadas por um "impeto meio fauve". E Bandeira representaria o sangue puro do Ceará. Navarra questionou o lugar do índio na pintura cearense e comparou Chico da Silva às impressões que teve quando teve contato pela primeira vez com a pintura de Cicero Dias, adjetivando as suas impressões escreveu:"ingenuidade lirica aplicada à pintura" e continuava as comparações dizendo "este índio é um Dali em estado de natureza” (Galvão 1985: 86)

Baratta, devolve dizendo que Navarra, de cearense, somente conhecia o Bandeira. Afirma que o mesmo não podia avaliar o quanto estava sendo feito em Fortaleza em termos de renovação da pintura, na busca da libertação na observação da natureza. E que em relação aos conceitos que Navarra apresentava sobre a pintura Mexicana, os trabalhos por eles realizados, estavam de acordo com a compreensão que estavam tendo da orientação da pintura, afim de chegarem a uma escola de pintura brasileira. E continuou:

Do melting-pot nordestino há um tipo, um resultante de fusão, perfeitamente caracterizado, temos um folklore próprio e rico, temos uma literatura nordestina (Zé Lins, Rachel, Graciliano, Fran), a mais brasileira, e, se continuarmos, nada nos impedirá de termos uma escola de pintura nordestina, que pelas determinantes econômicas, mesológicas e antropológicas, será também a mais brasileira de todo o Brasil. (ESTRIGAS, 2004: 55-56)

O que os dois críticos debatem entre seus textos não é a qualidade da pintura propriamente, mas o lugar que elas representam e para quem elas se apresentam, uma relação de poder entre os lugares que as interpretam. Baratta afirma no inicio do seu argumento que Navarra desconhece - mesmo sendo considerado um dos grandes críticos de arte do Brasil - o trabalho que estava sendo desenvolvido em Fortaleza e, que o no Ceará os artistas estavam em sintonia com as propostas contemporâneas em relação à pintura - sabia da onde falava e para quem falava, estava ciente da sua participação na arena política das artes. E qual teria sido a intenção de Mário ao evocar o conceito de melting-pot ? Para contrapor-se a noção de pureza apresentada por Navarra e, mostrar que no Ceará, os projetos em torno da renovação da pintura, sabiam-se resultado de uma fusão cultural? Que os artistas cearenses poderiam produzir uma arte brasileira tanto quanto os artistas da onde escrevia Navarra?

Neste texto para o jornal $O$ Estado, o melting-pot é usado como argumento na defesa da arte produzida no Ceará, enquanto arte brasileira. Talvez Navarra não tenha tido a oportunidade de ler a resposta elaborada por este crítico de arte, da cidade que acreditava ser tão distante. $O$ termo foi escrito em inglês, para mais uma vez demarcar que as leituras e interesses que circulavam, na cidade desconhecida por Navarra, faziam parte de um diálogo internacional. Assim, podemos tentar compreender como este conceito de fusão de culturas, foi importante para a afirmação política de artistas, que estavam circunscritos em uma realidade social diferente da dos artistas de cidades como Rio de Janeiro e São Paulo, por exemplo. Antônio Bandeira tem mais possibilidades de ter 
tido contato com o texto, de ter participado de momentos em que o tema do cadinho de raças foi colocado em pauta, na rodas de conversas entre artistas.

Navarra no seu texto fala da origem "enigmática" de Chico da Silva. Baratta responde dizendo que "não duvida em nada da sua origem indígena" e não admite a possibilidade de Chico da Silva ter sido influenciado pelas imagens da arte ocidental, mantendo-se originalmente índio e o mantém o artista no seu lugar de primitivo. Seria possível para o Chico da Silva ser índio e não ser primitivo, para o pensamento da época? Um índio artista urbano, é transformado em um problema para a critica de arte. Como definia-se o ser índio, no Brasil, nos anos de 1940? Era possível pensar arte brasileira e diferenças étnicas, nos meados do século $X X$ ? Os críticos em questão não sabiam como enquadrá-lo, Navarra expôs a seguinte conclusão:"O que importa é ele ser um exemplo maravilhoso do que existe em potencial na sensibilidade indígena como promessa de arte criadora"'(GALVÃO, 1986:86). Enquanto Baratta afirma a etnicidade de Chico da Silva, Navarra nega e o pensa como um sinal do potencial criativo da herança indígena, para o futuro da criação artística no Brasil.

O confronto entre estes dois críticos é um indicio do quão complexo era o uso da noção de cadinho, para pensar as artes brasileiras.Assim, é preciso historicizar este conceito de cadinho de raças que foi difundido no Brasil a partir da obra de Gilberto Freyre e, fez parte da elaboração do processo de formação de uma identidade nacional a partir da diversidade étnica no Brasil. Este conceito tem origem nos Estados Unidos, onde Freyre havia feito seus estudos com Franz Boas. No inicio do século XX, o escritor judeu Israel Zangwill, nascido em Londres filho de imigrantes Russos, escolheu o termo "Melting Pot" como titulo de uma peça de teatro. Essa peça foi encenada em Nova York em 1908. E dramatizava a aceitação dos imigrantes como americanos no cadinho de Deus, o grande melting pot aconteceria quando todas as raças da Europa estivessem fusionadas e refinadas. (BURKE, 2009: 47)

O cadinho de raças, proposto por Freyre, nos anos 1930, traria um olhar positivo para o mito das três raças, de acordo com Schwarcz, (1993):

O "cadinho de raças" surgia como uma nova forma de celebração do mito das raças - um novo instrumental para a utilização do mesmo termo, porém com um novo sentido -, mais evidente aqui do que em qualquer outro lugar. "Todo brasileiro, mesmo o alvo, de cabelo louro, traz na alma quando não na alma e no corpo, a sombra, ou pelo menos a pinta, do indígena ou do negro." (Freyre, op. cit., p. 307) O brasileiro era, portanto, o resultado sincrético de uma mistura bem-feita e original, cuja cultura homogênea e particular era também mista.

Gilberto Freyre se apropria deste conceito para explicar a formação do Brasil, a partir da tese de que não haviam diferentes raças humanas, mas sim diferentes culturas contrapondo-se a teoria evolucionista. $\bigcirc$ cadinho de raças metaforizava o Brasil como sendo fruto da mistura cultural entre brancos, negros e índios, uma atualização do mito das três raças. Ao homogeneizar as diferenças étnicas no processo de abrasileiramento das praticas culturais, a noção de cadinho provocou, por exemplo, a "desafricanização de elementos culturais, simbolicamente clareados" ( SCHWARCZ, 20I0: I2). Considerando esse argumento, questiono: para sua arte ser brasileira Chico da Silva deveria deixar de ser índio? Ou, continuando sendo índio, sua arte seria sempre inferior, posto que era considerada primitiva? Sendo índio ou não, era analfabeto e, por este motivo, seria 
apenas uma sensibilidade criativa, a ser notada como influência na formação da identidade nacional? Índio, pobre e analfabeto, Chico seria visto sempre como o outro e o exótico, não estando "pronto" para ser produto da cultura nacional?

E para Antônio Bandeira, artista negro, trazia o tema do cadinho como oferenda à sua cidade queimada do sol. $O$ objeto associado na sua função à sua metáfora. Esse cadinho de raças, de ferro e bronze, de corpo e alma era parte da sua arte, das obras que passavam a fazer parte da coleção do primeiro museu de arte de Fortaleza. No museu-cadinho de Bandeira temos: afeto, deslocamento, dúvidas, os tempos da vida, olhares, meditação, Fortaleza e gente, é feito de ferro e bronze, de corpo e alma e de raças. E principalmente, das lembranças que o ligam à sua história intima, ao seu pai. $O$ cadinho é o vestígio do processo criador, é a sua ferramenta de trabalho, são as técnicas com as quais ele operava com as cores, as ideias, as vidas, as praticas, os olhares e os seus sentimentos. No Brasil não se comentava sobre a cor da pele de Antônio Bandeira, talvez no abrasileiramento do artista, que morava em Paris, acreditassem não caber esta observação. Entretanto, Georges Mathieu artista francês ligado ao abstracionismo lirico, em uma das poucas vezes que citou o nome do artista, referiu-se ao Bandeira como um artista negro:

Reencontrávamos Bandeira, esse pintor negro brasileiro, de expressão hilária e sempre bem humorado, que também estava fascinado pela personalidade de Wols, e que eu procurava introduzir nos grupos de artistas. (COUTO, 2009: 8I)

Com as misturas do seu cadinho Bandeira teria tornado-se branco para o/no Brasil? Este objeto era o que mantinha os laços com a cidade e com a história familiar.Antes de embarcar para Paris, Bandeira havia pintado três retratos, "retrato de menino"6 em 1942, "auto-retrato no espelho" de 1945 e, em I946, pintou "auto-retrato na garrafa"7, este último quando vivia no Rio de Janeiro. No quadro de 1942, fica ambíguo, pelo titulo se é um registro dos tempos de menino, ou se é o retrato de um menino qualquer: um busto de menino negro, de olhar sereno e afirmativo. Quando um artista pincela seu autorretrato na tela, está inscrevendo sua imagem na trajetória da sua obra, registra, com este gesto, a maneira como quer ser visto e lembrado, elabora uma representação como escrita de si. Sobre o ato de pintar um autorretrato George Steiner (1993: I83 apud VENTURA, 2010) coloca:

o auto-retrato é a menos imitativa, a menos especular das construções estéticas. "Pintar-se a si próprio" é uma expressão densa de um sentido que nos apresenta o escritor ou o artista retomando a criação da sua própria personagem. (...) O auto-retrato é a expressão da sua compulsão de liberdade, da sua intenção agonística de se reapossar, de conseguir o domínio das formas e dos sentidos do seu próprio ser.

Nos dois quadros Bandeira está contido nos objetos que tem a qualidade de refletir a imagem: o espelho e a garrafa. Perto do espelho podemos ver a mesa, como suporte, um cachimbo e uma carteira de cigarros, outros objetos não identificados, marcados pelas cores, vermelho, azul, marrom e branco. A parede amarela e um fragmento da moldura da janela. No centro do quadro, no enqua-

6 Coleção Antônio Bandeira, acervo do MAUC.

7 Os quadros são da coleção do Governo do Estado do Ceará, acervo MAC, Centro de Arte e Cultura Dragão do Mar. 
dramento do espelho, seu rosto: um jovem negro com os cabelos soltos crescidos na franja. Olha de lado, observando-se no espelho, com semblante inquieto. Por ter escolhido a cor amarela, como predominante para o pano de fundo do quadro, produziu mais luz no ambiente e, por contraste, ressaltou os sentidos do seu próprio ser. Da garrafa, objeto do cotidiano, Bandeira aproveita o reflexo convexo para ampliar as mãos que escrevem. Um homem negro e forte sentado na escrivaninha, aparenta estar reflexivo. Ao fundo a parede da casa, um quadro, as linhas amarelas: a garrafa está sobre a mesa, diante do seu autor.

$\mathrm{Na}$ feitura do autorretrato, ensaia encontrar a si mesmo, produzir uma interpretação do momento vivido. Na experiência, de saber-se no mundo apresenta aspectos e fragmentos do seu lugar social, seleciona que pessoa, das gentes que o habitam, vai expor ao outros e a si. Bandeira mostra-se de casa para $\circ$ mundo, inquieto, pensativo e autor/ator da seu ser/estar no mundo. Nesse movimento, o artista mostra que no seu museu-cadinho é também um lugar de histórias de vida.A sua noção de cadinho, não é exatamente a mesma que vai servir ao Governo Federal Brasileiro, na tentativa de forjar uma identidade nacional brasileira que homogeniza e apaga as marcas singulares das diferentes culturas que habitam neste território definido como Brasil. No roteiro escrito por Bandeira para o filme "o colecionador de crepúsculos", onde contaria sua vida, escreveu: Falando ainda em cadinho, creio que fundindo homens e bichos, cidades, trens, navios, arvores e lixo, remexendo bem como no disco de Newton, se poderá conseguir uma confusão ou receita psicoplàstico poética que não é nada e é tudo. (ESTRIGAS, 200I:46)

O disco de Newton é uma ferramenta que serve para mostrar que a luz branca é formada de todas as cores, em alta rotação as cores se misturam e criam a ilusão de que o disco é todo branco. Newton trabalhou em diferentes experimentos para demonstrar que "a luz era uma mistura heterogênea de raios com diferentes refrangibilidades", SILVA e MARTINS (2003:56 e 6I) explicam que:

Para entendermos todos os aspectos envolvidos na argumentação de Newton, é importante compreendermos sua distinção teórica entre cor simples (ou primária) e cor composta.compreendermos sua distinção teórica entre cor simples (ou primária) e cor composta. Para desenvolver sua teoria, Newton criou um novo conceito de cor, distinguindo entre nossa sensação e as propriedades da luz em si. Ele estabeleceu cuidadosamente que raios diferentes de luz têm diferentes "disposições para exibir esta ou aquela cor particular". O mesmo tipo de luz sempre produz a mesma sensação, mas a mesma sensação pode ser produzida por diferentes tipos de luz. Nossos olhos não podem distinguir entre os dois tipos de luz. No entanto, elas podem ser distinguidas através de experimentos: a luz composta pode ser decomposta em duas ou mais componentes por um prisma, enquanto que a luz primária não. Segue-se desta definição que a luz branca não é simples - ela é composta pois pode ser decomposta em várias cores diferentes por um prisma.

O museu-cadinho não teria o poder de transformar a luz, apenas de decompor as suas diferentes cores? Ou teria o poder de iludir causando confusões nos sentidos? Teria este lugar de memória o compromisso de apresentar a heterogeneidade ou de forjar a homogeneidade? No caso da fabricação do patrimônio cultural no museu, a luz não é natural, ela é projetada. Este todo 
branco, que contém todas as heterogeneidades, não é possível. Assim, dependendo das sensações de quem projeta as luzes, algumas cores serão refletidas e outras serão absorvidas. Bandeira reflete uma cidade queimada do sol, feita com o cadinho que ganhou de presente do seu pai.Ao mesmo tempo projeta com a sua luz a vontade de garantir um lugar de memoria das artes, que faça pontes entre a sua cidade e o mundo.

\section{Bibliografia:}

BECKER, HOWARD S. Les Mondes de l'art. Champs des arts - Flammarion, Paris 2010. GALVÃO, Roberto. Chico da Silva e a Escola do Pirambu. Secretaria da Cultura de Fortaleza, Fortaleza, 1985.

CHAGAS, Mario.A imaginação museal:museu, memória e poder em Gustavo Barroso, Gilberto Freyre e Darcy Ribeiro. Rio de Janeiro: Ibram/Garamond, 2009.

BEZERRA, Carlos Eduardo de Oliveira.Adolfo Caminha: um polígrafo na literatura brasileira do século XIX (I885 - |897) - São Paulo: Cultura Acadêmica, 2009.

BURKE, Peter. Cultural Hybridity. Polity Press: Cambridge, 2009

ESTRIGAS, (Nilo de Brito Firmeza). O Salão de Abril de 1943 a 2009, $2^{\circ}$ Edição, atualizada e ampliada por Gilmar de Carvalho. Fortaleza, La Barca Editora, Secretaria da Cultura de Fortaleza, 2009.

COUTO, Maria de Fátima Morethy. A recepção da obra de Antônio Bandeira no exterior (1946-1967) In: Revista de História da Arte e da Arqueologia nº I. IFCH Unicamp, Campinas, 2009.

ESTRIGAS, Nilo de Brito Firmeza. Arte Ceará. Mário Baratta: o líder da renovação. Museu do Ceará, Secretaria da Cultura do Estado do Ceará. Fortaleza, 2004.

ESTRIGAS, Nilo de Brito Firmeza. Antônio Bandeira: a permanência do pintor. Imprensa Universitária, 200 I

ESTRIGAS, Nilo de Brito Firmeza.A fase renovadora da arte cearense. Fortaleza, Edições Universidade Federal do Ceará, 1983.

ESTRIGAS e DIAS, Milton.Antônio Bandeira: 25 anos depois. Fundação de Cultura e Turismo de Fortaleza, 1992.

GAY, Peter.A educação dos sentidos - A experiência burguesa: da rainha Vitória a Freud. São Paulo, Cia. das Letras, 1988

LIMA, Roberto Galvão. A Escola Invisível:Artes Plásticas em Fortaleza 1928 1958. Quadricolor editora: Fortaleza, 2008.

MICHAELIS, Dicionário de Português Online. Disponível em: http://michaelis.uol.com.br/moderno/portugues/index.php?lingua=portugues-portugues\&palavra=cadinho acessado em março 2012.

OLIVEIRA, Gerciane Maria da Costa. Chico da Silva: estudo sociológico sobre a manifestação de um talento artístico. 2010. 126 f. Dissertação (Mestrado em Sociologia). Universidade Federal do Ceará-UFC, Fortaleza, 2010.

RIOS, Kênia Sousa. Campos de concentração no Ceará: isolamento e poder na seca de 1932 - Fortaleza, Museu do Ceará, Secretaria da Cultura e Desporto do Ceará, 200 I 
VERLAINE, Julie. Les Galeries d'Art Contemporain à Paris. Une histoire culturelle du Marché de l'Art, I944-1970. Paris, Publication de la Sorbonne, 2012.

SCHWARCZ, Lilia Katri Moritz. Gilberto Freyre: adaptação, mestiçagem, trópicos e privacidade em 'Novo Mundo dos Trópicos' in: Mal-estar na Cultura - Departamento de Difusão Cultural - PROREXT-UFRGS Pós Graduação em Filosofia - IFCH - UFRGS, 20I0. http://www.difusaocultural.ufrgs.br/adminmalestar/ documentos/arquivo/Schwarcz\%20-\%20adaptacao\%20mesticagem\%20tropicos. pdf acessado em janeiro de 2013.

SCHWARCZ, Lilia Katri Moritz."COMPLEXO DE ZE CARIOCA Notas sobre uma identidade mestiça e malandra." I993 IN: http://www.anpocs.org.br/portal/ publicacoes/rbcs 00 29/rbcs 2903 acessado em 05 février 2012.

STEINER, George.Presenças reais.As artes do sentido.Lisboa:Editorial Presença, 1993 apud VENTURA, Susana Ramos. Da pintura à escrita: algumas considerações sobre "Manual de pintura e caligrafia”, Núcleo de Estudos lbéricos :Textos e debates sobre o Mundo Ibérico, 2010. In: http://nucleodeestudosibericos.wordpress.com/2010/01/28/ da-pintura-a-escrita-algumas-consideracoes-sobre-\%E2\%80\% $\mathrm{Cmanual-de-pintura-}$ -e-caligrafia\%E2\%80\%9D/ acessado em janeiro de 2013.

SILVA, Cibelle Celestino e MARTINS, Roberto de Andrade. A teoria das cores de newton: um exemplo do uso da história da ciência em sala de aula. In: Ciência e Educação. v.9 n. I, 2003 (53-65) http://www.scielo.br/pdf/ciedu/v9n l/05.pdf acessado em janeiro de 2013 